\title{
Limitations of the ARDS criteria during high-flow oxygen or non-invasive ventilation: evidence from critically ill COVID-19 patients
}

\author{
Michael Hultström ${ }^{1,2^{*}}$, Ola Hellkvist ${ }^{1}$, Lucian Covaciu ${ }^{1}$, Filip Fredén ${ }^{1}$, Robert Frithiof ${ }^{1}$, Miklós Lipcsey ${ }^{1,3}$, \\ Gaetano Perchiazzi ${ }^{1,3}$ and Mariangela Pellegrini ${ }^{1,3}$
}

\begin{abstract}
Background: The ratio of partial pressure of arterial oxygen to inspired oxygen fraction $\left(\mathrm{PaO}_{2} / \mathrm{F}_{1} \mathrm{O}_{2}\right)$ during invasive mechanical ventilation (MV) is used as criteria to grade the severity of respiratory failure in acute respiratory distress syndrome (ARDS). During the SARS-CoV2 pandemic, the use of $\mathrm{PaO}_{2} / \mathrm{F}_{1} \mathrm{O}_{2}$ ratio has been increasingly used in noninvasive respiratory support such as high-flow nasal cannula (HFNC) and non-invasive ventilation (NIV). The grading of hypoxemia in non-invasively ventilated patients is uncertain. The main hypothesis, investigated in this study, was that the $\mathrm{PaO}_{2} / \mathrm{F}_{1} \mathrm{O}_{2}$ ratio does not change when switching between MV, NIV and HFNC.

Methods: We investigated respiratory function in critically ill patients with COVID-19 included in a single-center prospective observational study of patients admitted to the intensive care unit (ICU) at Uppsala University Hospital in Sweden. In a steady state condition, the $\mathrm{PaO}_{2} / \mathrm{F}_{1} \mathrm{O}_{2}$ ratio was recorded before and after any change between two of the studied respiratory support techniques (i.e., HFNC, NIV and MV).

Results: A total of 148 patients were included in the present analysis. We find that any change in respiratory support from or to HFNC caused a significant change in $\mathrm{PaO}_{2} / \mathrm{F}_{1} \mathrm{O}_{2}$ ratio. Changes in respiratory support between NIV and MV did not show consistent change in $\mathrm{PaO}_{2} / \mathrm{F}_{1} \mathrm{O}_{2}$ ratio. In patients classified as mild to moderate ARDS during $\mathrm{MV}$, the change from HFNC to MV showed a variable increase in $\mathrm{PaO}_{2} / \mathrm{F}_{1} \mathrm{O}_{2}$ ratio ranging between 52 and $140 \mathrm{mmHg}$ (median of $127 \mathrm{mmHg}$ ). This made prediction of ARDS severity during MV from the apparent ARDS grade during HFNC impossible.

Conclusions: $\mathrm{HFNC}$ is associated with lower $\mathrm{PaO}_{2} / \mathrm{F}_{1} \mathrm{O}_{2}$ ratio than either NIV or MV in the same patient, while NIV and $\mathrm{MV}$ provided similar $\mathrm{PaO}_{2} / \mathrm{F}_{1} \mathrm{O}_{2}$ and thus ARDS grade by Berlin definition. The large variation of $\mathrm{PaO}_{2} / \mathrm{F}_{1} \mathrm{O}_{2}$ ratio indicates that great caution should be used when estimating ARDS grade as a measure of pulmonary damage during HFNC.
\end{abstract}

Keywords: Acute respiratory distress syndrome, Mechanical ventilation, High-flow oxygen, Non-invasive ventilation

\footnotetext{
*Correspondence: michael.hultstrom@mcb.uu.se

${ }^{1}$ Anaesthesiology and Intensive Care Medicine, Department of Surgical

Sciences, Uppsala University, Akademiska sjukhuset, ANOPIVA, Ing70, 2tr, 75185 Uppsala, Sweden

Full list of author information is available at the end of the article
}

\section{Introduction}

The Berlin definition of the acute respiratory distress syndrome (ARDS)[1] is clinically useful as index of both organ dysfunction and severity of hypoxemia $[2,3]$. There is growing interest in non-invasive respiratory support original author(s) and the source, provide a link to the Creative Commons licence, and indicate if changes were made. The images or other third party material in this article are included in the article's Creative Commons licence, unless indicated otherwise in a credit line to the material. If material is not included in the article's Creative Commons licence and your intended use is not permitted by statutory regulation or exceeds the permitted use, you will need to obtain permission directly from the copyright holder. To view a copy of this licence, visit http://creativecommons.org/licenses/by/4.0/. The Creative Commons Public Domain Dedication waiver (http://creativecommons.org/publicdomain/zero/1.0/) applies to the data made available in this article, unless otherwise stated in a credit line to the data. 
for acute hypoxemic respiratory failure [4]. The ongoing Corona Virus Infectious Disease 2019 (COVID-19) pandemic brought an even wider use of high-flow nasal cannula oxygen therapy (HFNC) and non-invasive ventilation (NIV) because of limited availability of mechanical ventilation (MV) [5]. While NIV provides a measurable positive end expiratory pressure (PEEP) that maybe consistent with the Berlin criteria, the level of PEEP generated by HFNC is uncertain $[6,7]$. In addition, the inspiratory fraction of oxygen $\left(\mathrm{F}_{\mathrm{I}} \mathrm{O}_{2}\right)$ is uncertain because of leakage and variable dead space volume.

This means that the current ARDS criteria for grading hypoxemia are difficult or impossible to apply in noninvasively ventilated patients [8]. However, despite lacking clinical evidence, ARDS criteria have been applied to patients not undergoing invasive mechanical ventilation [9]. Recent reports have indicated some applicability of a low $\mathrm{PaO}_{2} / \mathrm{F}_{\mathrm{I}} \mathrm{O}_{2}$ ratio during HFNC to predict mortality [10]. The main aim of the current study was to allow the accurate stratification of respiratory dysfunction during HFNC and NIV in COVID-19 ARDS patients by providing expected differences in $\mathrm{PaO}_{2} / \mathrm{F}_{\mathrm{I}} \mathrm{O}_{2}$ ratio upon a change in ventilatory strategy.

\section{Materials and methods}

$\mathrm{PaO}_{2} / \mathrm{F}_{\mathrm{I}} \mathrm{O}_{2}$ ratios were investigated in critically ill adult patients with COVID-19 admitted to the intensive care unit (ICU) at Uppsala University Hospital in Sweden from March 14, 2020 until January 14, 202 and included in a prospective observational cohort study due to COVID-19. During the most intense part of the pandemic, HFNC was used in regular wards up to $60 \mathrm{~L} /$ min of $60 \%$ oxygen at our hospital. Reaching this level, patients were transferred to the ICU where increasing oxygen supplementation, prone position or a change of respiratory support would be performed. Actual flow rate was $50 \pm 9 \mathrm{~L} / \mathrm{min}$ at $66 \pm 13 \%$ oxygen during step-up from HFNC, and $44 \pm 10 \mathrm{~L} / \mathrm{min}$ at $55 \pm 13 \%$ oxygen during step-down to HFNC. Standard starting PEEP during NIV was between 5 and $10 \mathrm{cmH}_{2} \mathrm{O}$, and during MV 7 to $14 \mathrm{cmH}_{2} \mathrm{O}$ (Table $1 \mathrm{~A}$ and B). During step-down, a PEEP below $10 \mathrm{cmH}_{2} \mathrm{O}$ during $\mathrm{MV}$ would be matched with a similar PEEP in NIV (Table 1A and B). The corresponding changes in PEEP are reported in Table $1 \mathrm{C}$.

We analyzed the $\mathrm{PaO}_{2} / \mathrm{F}_{\mathrm{I}} \mathrm{O}_{2}$ ratio before a change in respiratory strategy compared to 30 to $60 \mathrm{~min}$ after a switch in respiratory support. Patients who were not in steady state ventilation, or who did not have a blood gas analysis within a reasonable time were excluded. For each included patient, the first two changes of respiratory support were used, resulting in six comparisons. (1) HFNC-to-NIV; (2) HFNC-to-MV; (3) NIV-to-HFNC; (4) NIV-to-MV; (5) MV-to-HFNC; (6) MV-to-NIV.
Table 1 Estimated positive end-expiratory pressure (PEEP) and change of PEEP during a change of ventilatory strategy

\begin{tabular}{llll}
\hline 1st Strategy & \multicolumn{2}{l}{ 2nd Strategy } & \\
\cline { 2 - 4 } & \multicolumn{1}{c}{ HFNC } & NIV & MV \\
\hline A: First strategy PEEP & $\left(\mathrm{CmH}_{2} \mathrm{O}\right)$ & & 3 \\
HFNC & - & 3 & $7.1 \pm 2.1$ \\
NIV & $6.3 \pm 1.4$ & - & - \\
MV & $7.7 \pm 2.1$ & $7.1 \pm 1.8$ & \\
B: Second strategy PEEP $\left(\mathrm{cmH}_{2} \mathrm{O}\right)$ & & $11.3 \pm 4.0$ \\
HFNC & - & $5.8 \pm 1.2$ & $13.1 \pm 2.9$ \\
NIV & 3 & - & - \\
MV & 3 & $6.5 \pm 1.6$ \\
C: Estimated change in PEEP $\left(\mathrm{cmH}_{2} \mathrm{O}\right)$ & & \\
HFNC & - & $2.8 \pm 1.2$ & $8.3 \pm 4.0$ \\
NIV & $-3.3 \pm 1.4$ & - & $6.0 \pm 3.2$ \\
MV & $-4.7 \pm 2.1$ & $-0.5 \pm 2.0$ & -
\end{tabular}

The changes were from the first strategy to the second strategy that were either of high-flow nasal cannula (HFNC), non-invasive ventilation (NIV) or invasive mechanical ventilation (MV). The PEEP during HFNC was estimated to $3 \mathrm{cmH}_{2} \mathrm{O}$. A: PEEP before the change of strategy. B: PEEP after the change of strategy. C: Change in PEEP

\section{Results}

Two-hundred fifty-two changes of respiratory support in 148 patients were recorded. Median age was $66(\mathrm{IQR}=55-73)$ years, $25 \%$ were women. Body mass index was 29 (25-33), and $26 \%$ of the included patients had a previous diagnosis of chronic pulmonary disease. Patients were admitted after 10 (8-12) days of symptoms with a simplified acute physiology score 3 (SAPS3) of $53(47-59)$ and $\mathrm{PaO}_{2} / \mathrm{F}_{\mathrm{I}} \mathrm{O}_{2}$ ratio of 114 (101-148) mmHg.

Changes to or from HFNC were biased to lower $\mathrm{PaO}_{2}$ $/ \mathrm{F}_{\mathrm{I}} \mathrm{O}_{2}$-ratio during HFNC, NIV-HFNC: $-29(-15$ to -60$)$ $\mathrm{mmHg}$, and HFNC-NIV: 41(21-65) $\mathrm{mmHg}$, and more pronounced in HFNC-MV $-45(-26$ to -28$) \mathrm{mmHg}$, and HFNC-MV 48(23-73) mmHg (Figs. $1 \mathrm{~A}$ and C, 2A, $\mathrm{B}, \mathrm{C}$ and $\mathrm{E})$. On the other hand, changes between NIV and MV did not cause consistent differences in $\mathrm{PaO}_{2} /$ $\mathrm{F}_{\mathrm{I}} \mathrm{O}_{2}$ ratio NIV-MV: $11(-7.5-38) \mathrm{mmHg}$ and MV-NIV: $-4(-23-8) \mathrm{mmHg}$ (Figs. $1 \mathrm{~B}$ and $\mathrm{D}, 2 \mathrm{D}$ and $\mathrm{F}$ ). All comparisons showed positive correlations between the strategies (Fig. 2 A, C, D, E and F), except HFNC-MV $\left(R^{2}=0.12, P=0.52\right.$, Fig. $\left.2 \mathrm{~B}\right)$. The correlations improved during step-down from MV to NIV, or MV and NIV to HFNC (Fig. 2C, E and F).

The effective delivery of PEEP is considered to be one of the most important differences between HFNC, NIV and $\mathrm{MV}$, which is also an important determinant of the amount of open lung and thereby the $\mathrm{PaO}_{2} / \mathrm{F}_{\mathrm{I}} \mathrm{O}_{2}$ ratio. Therefore, we analyzed the correlation between the change in $\mathrm{PaO}_{2} / \mathrm{F}_{\mathrm{I}} \mathrm{O}_{2}$ and the change in PEEP for all 

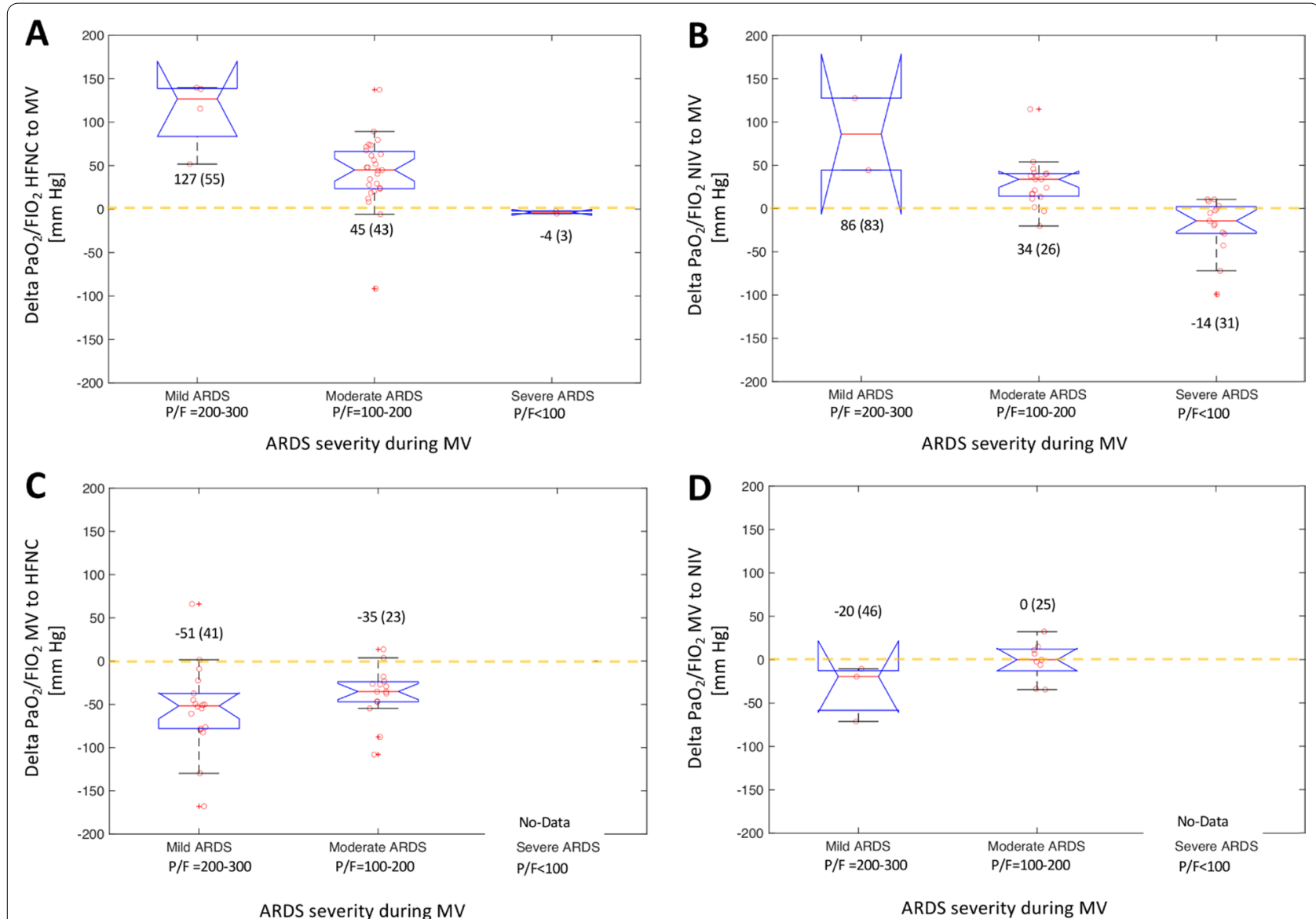

Fig. 1 Change in $\mathrm{PO}_{2} / \mathrm{F}_{1} \mathrm{O}_{2}$ after a change in respiratory support in 148 critically ill COVID-19 patients grouped by ARDS severity during mechanical ventilation (MV) based on the Berlin definition. A HFNC to MV. B NIV to MV. C MV to HFNC. D MV to NIV

individual strategy changes (Fig. 3). It is noteworthy that the correlation is good, but there is a large residual variation.

This resulted in reassignments between ARDS grades, showing general improvements in oxygenation during step-up from HFNC to NIV or MV. Mostly improvement during step-up from NIV to MV, although several patients showed worsened ARDS grade in this setting (Table 2A). Finally, worsened oxygenation, and increased ARDS grade was seen during step-down to HFNC from either MV or NIV, while step-down from MV to NIV only resulted in the reassignment of one patient in either direction (Table 2B).

\section{Discussion}

The primary finding of this study is the high variability in the effect on $\mathrm{PaO}_{2} / \mathrm{F}_{\mathrm{I}} \mathrm{O}_{2}$ ratio after changing ventilation strategy. Considering ARDS grade under $\mathrm{MV}$ as gold standard, $\mathrm{PaO}_{2} / \mathrm{F}_{\mathrm{I}} \mathrm{O}_{2}$ ratio during HFNC could not reliably predict ARDS severity. The present findings may provide a rationale for using $\mathrm{PaO}_{2} / \mathrm{F}_{\mathrm{I}} \mathrm{O}_{2}$ as ARDS criteria during NIV for decisions related to intubation or for prognosis but suggest great caution for its use during HFNC.

The main physiological reason for these findings is probably the efficiency of PEEP in counteracting alveolar collapse and concomitant shunt, as indicated by the excellent correlation between the change in estimated PEEP and the change in $\mathrm{PaO}_{2} / \mathrm{F}_{\mathrm{I}} \mathrm{O}_{2}$ ratio. However, with a remaining variation of around $65 \%$ even the change in PEEP cannot reliably predict the result of a change in ventilatory strategy. Interestingly, $\mathrm{PaO}_{2} / \mathrm{F}_{\mathrm{I}} \mathrm{O}_{2}$ ratio during step-down was markedly better, which probably indicates a well-recruited lung but also the fact that step-down happens when the lung has recovered to some degree. An additional factor which is well-known to affect $\mathrm{PaO}_{2} / \mathrm{F}_{\mathrm{I}} \mathrm{O}_{2}$ ratio is inspired oxygen, which we have not controlled for [11]. This means that some of the difference in $\mathrm{PaO}_{2} / \mathrm{F}_{\mathrm{I}} \mathrm{O}_{2}$ ratio is probably caused by changes in ventilation/perfusion mismatch caused by the change of respiratory strategy. While this could be controlled using a $\mathrm{F}_{\mathrm{I}} \mathrm{O}_{2}$ of 1.0 , this, in turn, would tend 

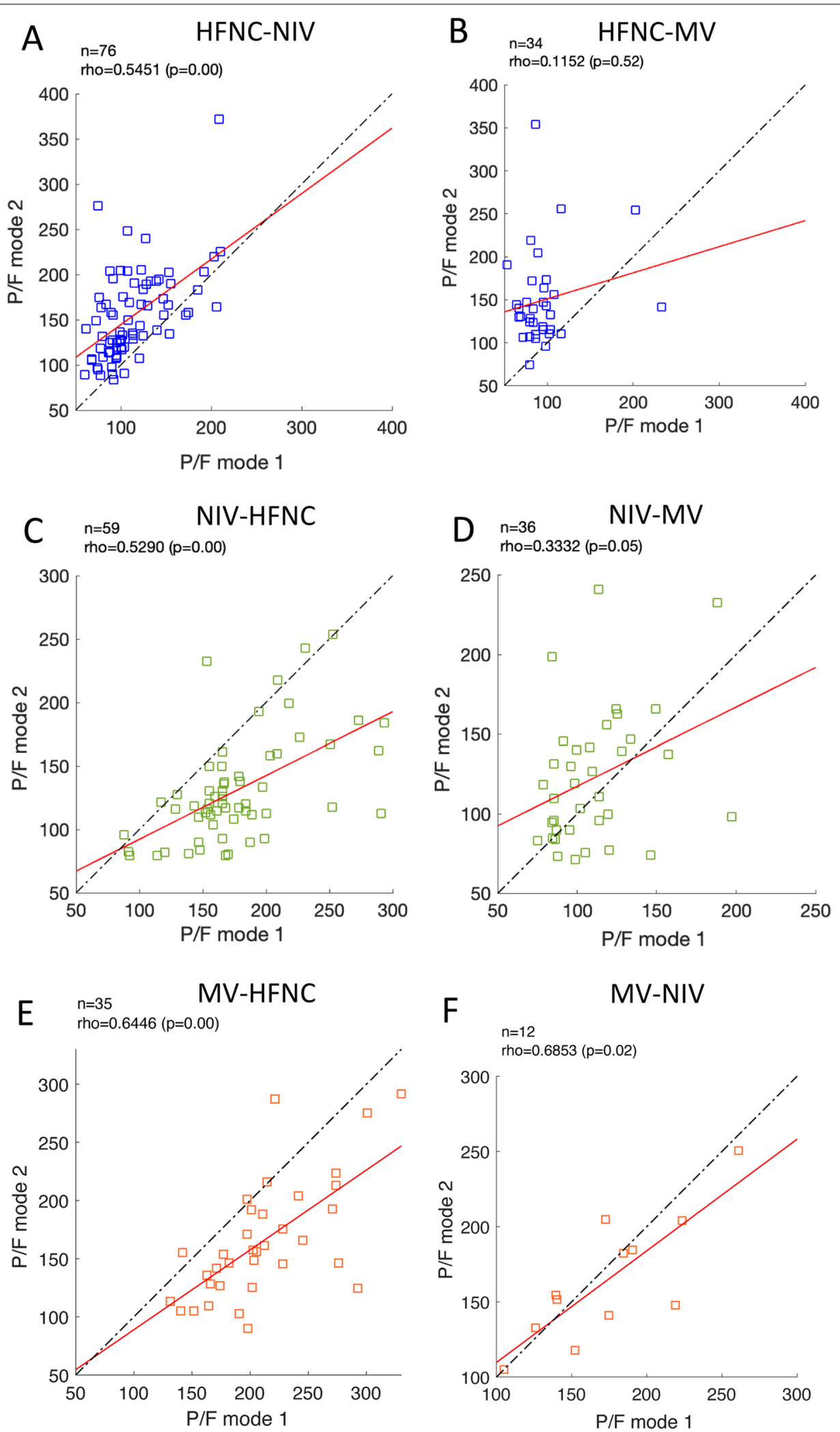

Fig. 2 Correlation of $\mathrm{PaO}_{2} / \mathrm{F}_{1} \mathrm{O}_{2}$ ratio before and after a change in ventilatory support in 148 critically ill COVID-19 patients. The six tested groups were: A HFNC-to-NIV; B HFNC-to-MV; C NIV-to-HFNC; D NIV-to-MV; E MV-to-HFNC; F MV-to-NIV. Rho and P-value calculated using Spearman rank correlation 


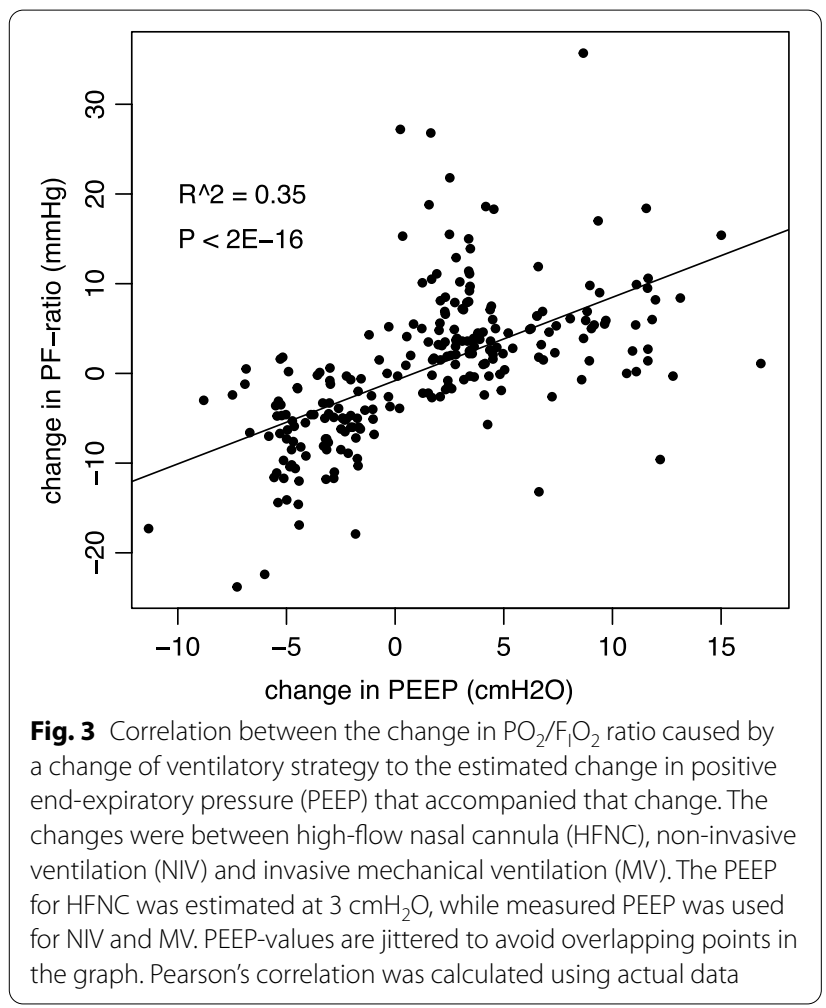

Table 2 The number of patients who are reassigned to a new grade of acute respiratory distress syndrome (ARDS, Mild: 200-300 mmHg, Moderate: $100-200 \mathrm{mmHg}$, and Severe: $<100 \mathrm{mmHg}$ ) during a change in ventilatory strategy

\begin{tabular}{llll}
\hline 1st Strategy & \multicolumn{2}{l}{ 2nd Strategy } & \\
\cline { 2 - 4 } & HFNC & NIV & MV \\
\hline A:Decreased ARDS grade & & $25(74 \%)$ \\
HFNC & - & $42(55 \%)$ & $10(28 \%)$ \\
NIV & $1(2 \%)$ & - & - \\
MV & $1(3 \%)$ & $1(8 \%)$ & $1(3 \%)$ \\
B:Increased ARDS grade & - & $1(1 \%)$ & $5(14 \%)$ \\
HFNC & $20(34 \%)$ & - & - \\
NIV & $14(40 \%)$ & $1(8 \%)$ & \\
MV &
\end{tabular}

The changes were from the first strategy to the second strategy that were either of high-flow nasal cannula (HFNC), non-invasive ventilation (NIV) or invasive mechanical ventilation (MV). Patients who decrease their ARDS grade, that improve in oxygenation are reported in $\mathbf{A}$, and those who increase ARDS grade, or show worse oxygenation in $\mathbf{B}$

to increase absorption atelectasis and therefore the true shunt fraction especially in HFNC [12]. Further, not only the respiratory strategies used, but also the respiratory settings are known to affect $\mathrm{PaO}_{2} / \mathrm{F}_{\mathrm{I}} \mathrm{O}_{2}$ ratio [13]. This means that the mandatory change from spontaneous ventilation to controlled ventilation at intubation will affect the results as well. The relationship between $\mathrm{PaO}_{2} / \mathrm{F}_{\mathrm{I}} \mathrm{O}_{2}$ and $\mathrm{F}_{\mathrm{I}} \mathrm{O}_{2}$ is influenced by multiple factors, such as the intrapulmonary shunt, arterio-venous difference of oxygen, partial pressure of arterial carbon dioxide, respiratory quotient and hemoglobin as well as the onset of absorption atelectasis [14]. The recognition of these physiological mechanisms as well as our results should prompt the development of more standardized procedures for grading hypoxemia and ARDS severity.

The current study had some limitations. The study focused exclusively on $\mathrm{PaO}_{2} / \mathrm{F}_{\mathrm{I}} \mathrm{O}_{2}$ ratio as a measure of respiratory function, not taking into account the complexity and the multifactorial nature of hypoxic acute respiratory failure and of its management as, for instance, the use of prone positioning, the level of sedation, muscle relaxation or other pharmaceutical interventions. However, when referring to the $\mathrm{PaO}_{2} /$ $\mathrm{F}_{\mathrm{I}} \mathrm{O}_{2}$ ratio in our clinical practice as well as in the Berlin definition of ARDS [1], the $\mathrm{PaO}_{2} / \mathrm{F}_{\mathrm{I}} \mathrm{O}_{2}$ ratio is used as an independent variable, not contextualized to, for instance, patients' position, hemodynamic, muscle relaxation, sedation. Further, as a single center study, local clinical routines may influence the generalizability of the results.

In conclusion, $\mathrm{PaO}_{2} / \mathrm{F}_{\mathrm{I}} \mathrm{O}_{2}$ ratio, in itself, is not sufficient to grade hypoxemia in ARDS patients during HFNC. $\mathrm{PaO}_{2} / \mathrm{F}_{\mathrm{I}} \mathrm{O}_{2}$ ratio during NIV is a reasonable estimate for actual ARDS grade during MV. There are large individual variations in the effect of changes in ventilatory modality that suggests future ARDS definitions should treat respiratory support strategies separately. Importantly, our findings indicate that clinical trials investigating noninvasive respiratory support in ARDS patients can lead to misinterpretation of these patients' outcomes. Additional prospective studies of $\mathrm{PaO}_{2} / \mathrm{F}_{\mathrm{I}} \mathrm{O}_{2}$ ratio during $\mathrm{HFNO}$ will be needed to fully understand the relation of $\mathrm{PaO}_{2} /$ $\mathrm{F}_{\mathrm{I}} \mathrm{O}_{2}$ ratio to outcomes in patients with and without COVID-19.

\section{Acknowledgements \\ The authors thank research nurses Joanna Wessbergh and Elin Söderman for their expertise in compiling patient data.}

\section{Authors' contributions}

All authors participated in project design and planning. $\mathrm{MH}, \mathrm{OH}, \mathrm{RF}, \mathrm{ML}$ and MP collected data. MP and MH wrote the first draft. All authors revised the paper and approved the final version for publication.

\section{Funding}

Open access funding provided by Uppsala University. The study was funded by the SciLifeLab/Knut and Alice Wallenberg national COVID-19 research program (M.H.: KAW 2020.0182, KAW 2020.0241), the Swedish Heart-Lung Foundation (M.H.: 20210089, 20190639, 20190637, and G.P.: 20200877 and 20200825), the Swedish Research Council (R.F.: 2014-02569, 2014-07606 and G.P.: 2018-02438). The Swedish Society for Medical Research (M.P. 463402221) and the Swedish Society of Medicine (M.P. SLS-959793) and Alvar Gullstrand research grant (G.P.: ALF-938050). Funding bodies had no role in the design 
of the study, collection and interpretation of data or in the writing of the manuscript.

\section{Availability of data and material}

Data are available from the corresponding author on reasonable request (https://doi.org/10.17044/scilifelab.14229410).

\section{Declarations}

\section{Ethics approval and consent to participate}

The National Ethical Review Agency approved the study (EPM; No. 202001623). The Declaration of HELSINKI and its subsequent revisions were followed. Written informed consent was obtained from the patients when possible. Otherwise, informed consent was firstly asked to next to kin and later confirmed by patients if feasible.

\section{Consent for publication}

Not applicable.

\section{Competing interests}

The authors declare that they have no competing interests.

\section{Author details}

${ }^{1}$ Anaesthesiology and Intensive Care Medicine, Department of Surgical Sciences, Uppsala University, Akademiska sjukhuset, ANOPIVA, Ing70, 2tr, 75185 Uppsala, Sweden. ${ }^{2}$ Integrative Physiology, Department of Medical Cell Biology, Uppsala University, Uppsala, Sweden. ${ }^{3}$ Hedenstierna Laboratory, Department of Surgical Sciences, Uppsala University, Uppsala, Sweden.

Received: 14 December 2021 Accepted: 16 February 2022

Published online: 07 March 2022

\section{References}

1. Force ADT, Ranieri VM, Rubenfeld GD, Thompson BT, Ferguson ND, Caldwell E, Fan E, Camporota L, Slutsky AS. Acute respiratory distress syndrome: the Berlin definition. JAMA. 2012;307(23):2526-33.

2. Martin-Rodriguez F, Lopez-Izquierdo R, Del Pozo VC, Delgado-Benito JF, Ortega GJ, Castro Villamor MA, Sanz-Garcia A. Association of prehospital oxygen saturation to inspired oxygen ratio with 1-, 2-, and 7-day mortality. JAMA Netw Open. 2021;4(4):e215700.

3. Bellani G, Laffey JG, Pham T, Fan E, Brochard L, Esteban A, Gattinoni L, van Haren F, Larsson A, McAuley DF, et al. Epidemiology, patterns of care, and mortality for patients with acute respiratory distress syndrome in intensive care units in 50 countries. JAMA. 2016:315(8):788-800.

4. Hill NS, Ruthazer R. Predicting outcomes of high-flow nasal cannula for acute respiratory distress syndrome. An index that ROX. Am J Respir Crit Care Med. 2019;199(11):1300-2.

5. Ferguson ND, Pham T, Gong MN. How severe COVID-19 infection is changing ARDS management. Intensive Care Med. 2020;46(12):2184-6.

6. Chertoff J. High-flow oxygen, positive end-expiratory pressure, and the Berlin definition of acute respiratory distress syndrome: are they mutually exclusive? Am J Respir Crit Care Med. 2017;196(3):396-7.

7. Spoletini G, Alotaibi M, Blasi F, Hill NS. Heated humidified high-flow nasal oxygen in adults: mechanisms of action and clinical implications. Chest. 2015:148(1):253-61.

8. Bellani G, Pham T, Laffey JG. Missed or delayed diagnosis of ARDS: a common and serious problem. Intensive Care Med. 2020;46(6):1180-3.

9. Rochwerg B, Brochard L, Elliott MW, Hess D, Hill NS, Nava S, Paolo Navalesi Members Of The Steering Committee, Antonelli M, Brozek J, Conti G, et al. Official ERS/ATS clinical practice guidelines: noninvasive ventilation for acute respiratory failure. Eur Respir J. 2017;50(2):1602426.

10. Ranieri VM, Tonetti T, Navalesi P, Nava S, Antonelli M, Pesenti A, Grasselli G, Grieco DL, Menga LS, Pisani L, et al. High flow nasal oxygen for severe hypoxemia: oxygenation response and outcome in COVID-19 patients. Am J Respir Crit Care Med. 2021;205(4):431-9.

11. Aboab J, Louis B, Jonson B, Brochard L. Relation between $\mathrm{PaO} 2 /$ FIO2 ratio and FIO2: a mathematical description. Intensive Care Med. 2006:32(10):1494-7.
12. Shapiro BA, Cane RD, Harrison RA, Steiner MC. Changes in intrapulmonary shunting with administration of 100 percent oxygen. Chest. 1980;77(2):138-41.

13. Ferguson ND, Kacmarek RM, Chiche JD, Singh JM, Hallett DC, Mehta S, Stewart TE. Screening of ARDS patients using standardized ventilator settings: influence on enrollment in a clinical trial. Intensive Care Med. 2004;30(6):1111-6.

14. Gowda MS, Klocke RA. Variability of indices of hypoxemia in adult respiratory distress syndrome. Crit Care Med. 1997;25(1):41-5.

\section{Publisher's Note}

Springer Nature remains neutral with regard to jurisdictional claims in published maps and institutional affiliations.
Ready to submit your research? Choose BMC and benefit from:

- fast, convenient online submission

- thorough peer review by experienced researchers in your field

- rapid publication on acceptance

- support for research data, including large and complex data types

- gold Open Access which fosters wider collaboration and increased citations

- maximum visibility for your research: over 100M website views per year

At BMC, research is always in progress.

Learn more biomedcentral.com/submissions 